\title{
A comunicação como conhecimento
}

Cristina Baccin

Professora Titular de Comunicação Social da Universidade Nacional do Centro da Faculdade de Ciências Sociais - FACSO.

Provincia de Buenos Aires, Unicen, Argentina.

E-mail: cbaccin@soc.unicen.edu.ar e cbaccin@infovia.com.ar

\section{O conhecimento utilizado como recurso para o desenvolvimento de novos espaços sociais}

Os acontecimentos que eclodiram em dezembro de 2001 na Argentina representam um ponto de inflexão importante. Vinculado à radicalização da aplicação do sistema neoliberal em um território nacional, afetou desde os aspectos mais complexos da macroeconomia até os mínimos detalhes da vida cotidiana dos habitantes desse país.

A diminuição da qualidade de vida da maioria dos habitantes implicou, no plano imediato e cotidiano, a restrição à satisfação das necessidades básicas, ao acesso aos mais variados bens, às movimentações, às rotinas, aos intercâmbios. Ocorreu, em geral, a quebra da possibilidade de planejar o futuro, com uma particularidade: o retrocesso se explicitou vertiginosa e aceleradamente no contexto de uma profunda incerteza. Num breve período evidenciou-se a ruptura dos acordos institucionalizados: desde os acordos entre cidadãos e governantes, os quais implicam o funcionamento da democracia representativa, até os mais formais, cuja existência ninguém questionava, como por exemplo o intercâmbio econômico realizado com o dinheiro.

Pretendo refletir sobre algumas noções (como crise, instituições - em particular, o plano instituinte, ou seja, plano da criação das instituições - e o conhecimento) para repensar as articulações do campo da comunicação e da educação, a partir da situação eclodida na Argentina em dezembro de 2001, até a perspectiva de suas potencialidades.

\section{ESPAÇO DE RECRIAÇÃO}

A capacidade de articular ou obstaculizar a ação humana, que é característica das instituições, parece invisível aos olhos do indivíduo/sujeito, em função 
do enquadramento e da inserção das instituições nas nossas sociedades. O fator menos perceptível é talvez o de que as instituições são criação humana, sendo, portanto, sua racionalidade e legitimidade inquestionáveis. Ficam imperceptíveis no "imaginário social instituinte, que cria a instituição em geral (a forma instituição) e as instituições particulares da sociedade consideradas imaginação radical do ser humano singular"1.

Nessa perspectiva, as instituições são organizadoras do sentido da vida humana em comum e também a obra do imaginário social que institui (instituinte). Enquanto criações e criadoras, elas contêm intrinsecamente sua própria potencialidade de se modificar e serem modificadas.

A possibilidade de ruptura das próprias instituições é possível em nossas sociedades, à medida que se faz explícita sua condição de criação humana.

O duplo jogo entre o instituído - aquilo que está estabelecido (papel que era cumprido pelo Estado como o espaço da lei) - e o instituinte - o espaço no qual "a fala social fica liberada" ${ }^{2}$ é intrínseco às instituições. No entanto, trata-se de um jogo cujas regras são tácitas, opacas na maioria das vezes. A possibilidade de modificar as relações de poder por cima, por baixo ou atravessando as hierarquias e as normas explícitas, raramente sobressai em tempos de estabilidade, quando a continuidade é a modalidade do pensamento predominante.

A crise recente na Argentina tem posto em evidência profunda, em primeiro lugar, a existência das instituições como determinantes do cotidiano. Em segundo lugar, abriu caminho para que a dimensão instituinte aflorasse. Por exemplo, impediam-se ações cotidianas como comprar mantimentos básicos, porque não existia dinheiro, mesmo que o dinheiro dos salários fosse creditado, simbolicamente, nos caixas de poupança dos trabalhadores, numa espécie de contrafação dos aspectos até aquele momento considerados normais, baseados em acordos formalizados entre empresas, bancos, Estado e outras organizações.

A complexidade institucional aparece como obstacularizadora da nãosatisfação de uma necessidade básica como a alimentação. Nessa complexidade, aparecem também como responsáveis as empresas, os bancos, os organismos financeiros internacionais, o Estado e, em especial, o sistema de governo. Como corporalidade manifesta aparecem: o Banco Mundial, o FMI - Fundo Monetário Internacional e a OCDE - Organização para Cooperação e Desenvolvimento Econômico, os quais deixam de ser siglas fechadas, cujo sentido só alguns economistas podiam decifrar. Elas passam a se corporificar através de cifras concretas, numa dívida externa cuja composição parecia não estar presente na

1. CASTORIADIS, Cornelius. Figuras de lo pensable (Figuras do pensamento). Buenos Aires: FCE, 2001. p. 93-177.

2. LAPASSADE, G. Grupos, organizaciones e instituciones. La transformación de la burocracia (Grupos, organizações e instituições. A transformação da burocracia). Barcelona: Gedisa, 1999. p. 18. vida cotidiana imediata, ainda que seu princípio de multiplicação provenha da última ditadura militar (1976-1983).

A ilusória estabilidade econômica e política, que outorgou o longo período da presidência Menem (1989-1999), alimentou a idéia de linearidade e continuidade que implicaram uma certa estabilidade e regularidade na vida cotidiana. Os golpes, as fortes rupturas do sistema, que haviam sido as modalidades mais freqüentes na história do país, pareciam não ter lugar num sistema que pretendia sustentar-se na simplicidade de uma fórmula: 1 = 1 ( 1 peso argentino = 1 dólar americano). 
A quebra institucional iniciada com o presidente De La Rua (em 2001), mediante o congelamento do uso do dinheiro, e a declaração do estado de sítio permitiram, por um lado, que a cidadania assumisse um papel ativo como potencial instituinte que reclamava mudanças e, por outro, evidenciou que se pretendia negar e burlar a existência de contratos e acordos instituídos, a partir do próprio Estado, através de diferentes medidas operacionais que foram ficando mais e mais complexas, tornando o espaço estatal um espaço de desordem, organizado em bolsões de poder.

Com a quebra do instituído, a dimensão pública da cidadania passa a cobrar e assumir um lugar ante o caos como vazio ${ }^{3}$; o que se dava como certo, em poucos dias desaparece, esconde-se, mas, ao mesmo tempo, torna transparente a característica escondida de opacidade das instituições como articuladoras, mediadoras ou exploradoras do bem comum, do bem público.

Nesse espaço/tempo social de vertiginosa mudança das condições de vida, o que se dava como certo é posto em questão. A vida cotidiana, o lugar das ações que se produziam com regularidade, sofre uma ruptura. A comunidade de sentido, que nos provê dos parâmetros de interpretação, não pode lançar mão de seu acervo histórico para resolver os problemas, já que os que aparecem são de natureza distinta e obrigam à busca de um novo conhecimento. A aparição de novos problemas requer outras instâncias de resolução e quebra a regularidade que leva o sujeito a sentir-se plenamente responsável: "a aparição de depósitos de sentido e de instituições históricas libera o indivíduo da pesada carga de solucionar os problemas da experiência e os atos que emergem, como se fosse pela primeira vez, em situações particulares. [...] Essa é a pré-condição para que os atos sejam transformados em instituições sociais"4. Mas aí, justamente, os depósitos de sentido estavam em pleno caos, no vazio.

Diante dessa incerteza que manifestava a impossibilidade de projetar temporalmente as ações, começa a instalar-se a necessidade de resolver novos problemas, recriando sentido: "a constituição subjetiva do sentido é a origem de todos os acervos sociais de conhecimento, os depósitos históricos de sentido nos quais podem se apoiar as pessoas" .

\section{O CONHECIMENTO: UM BEM NÃO RECONHECIDO}

"O homem, o ser humano ideal, manifesta-se em situações de crise, mas de crise real, quando tudo se derruba. [...] Porque a crise... o problema que foi apresentado é 'agora eu tenho que valer o que realmente valho'. E ocorre. Acontece. A normalidade é a inimiga do ser humano", disse recentemente o escritor Saramago ${ }^{6}$.

A ruptura da regularidade da vida cotidiana implicou a obrigatória necessidade de compartilhar conhecimentos a fim de resolver problemas: os interlocutores, em primeira e única instância, eram as instituições, as quais estavam cegas, surdas e mudas. E a resolução de problemas se direcionou para as mesmas instituições, cuja labiríntica complexidade se manifesta ante o cidadão comum, que não opta
3. No sentido recuperado por Castoriadis, Figuras de lo pensable..., op. cit., p. 273ss, da terminologia grega inicial: caos, não como desordem, mas sim como vazio.

4. BERGER, P. L.; LUCKMANN, T. Modernidad, pluralismo y crisis de sentido (Modernidade, pluralismo e crises de sentido). Barcelona: Paidós, 1997. p. 36.

5. Ibid., p. 37

6. Le Monde Diplomatique (ed. espanhola). Diálogo entre José Saramago e Ignácio Ramonet, em julho de 2002. 
por soluções violentas, mas pela instância burocrática da reclamação, até recorrer a uma das instâncias institucionais mais poderosas, mas muito escondida, como é o caso do Poder Judiciário. Funcionários quase desconhecidos na agenda pública começam a ser conhecidos, do mesmo modo que a figura principal do Poder Executivo, ou o gabinete do governo do momento.

Esse conhecimento de percursos burocráticos se produz sobre a base de problemas que requerem ação. "Os problemas afloram ao mesmo tempo, provenientes da ação social interativa, de maneira que as soluções devem se encontrar também em comum. Tais soluções podem objetivar-se num certo número de formas possíveis, mediante sinais, instrumentos, elaborações, mas, sobretudo, através das formas comunicativas de uma linguagem, ficando assim disponíveis para outros ${ }^{7}$." Esse conhecimento que se produz intersubjetivamente sobre a base de problemas comuns assume a importância de uma oportunidade para que a dimensão instituinte, ou seja, a capacidade de construir instituições, se faça explícita e assuma presença pública, quer através de formas inéditas de protesto e reclamação (os panelaços), quer através do fato de assumir responsabilidade sobre novas formas organizativas, como as diferentes modalidades de recuperação de fábricas falidas.

"A liberação do instituinte na sociedade, que cria novas formas de vida social e que inventa, de forma coletiva, métodos de regulação", tal como afirma Lapassade $^{8}$, é o marco da recuperação, com diferentes modalidades de organização (cooperativa, controle operário), de 107 fábricas falidas nos últimos dois anos.

É a maneira de criar novas ações de institucionalização, a partir da força do conhecimento, resultado de processos complexos, como a dúvida e a perda da organização dos sentidos.

Até a aparição do conflito, fatos como a organização financeira de uma empresa ou a desaparição do Estado, o qual havia sido, historicamente, ameaçador na sociedade argentina (em todos os sentidos, para gerar condições de desenvolvimento econômico, reprimir ou criar possibilidades de aplicação do neoliberalismo in extenso), não eram visíveis.

O conhecimento pode ser considerado um bem quando partimos da perspectiva de sua economia. Nesse contexto de crise, manifesta-se como produção de um bem comum. É verdade que sua principal característica é a intangibilidade, mas sua relevância pode ser dimensionada. O conhecimento é bem intangível quando se gera e distribui de modo independente das instituições (o que se cria, como neste caso, na base das necessidades de resolução de uma crise). Seu

7. BERGER, P. L.; LUCKMANN, T. Modernidad..., op. cit., p. 35 .

8. LAPASSADE, G. Grupos, organizaciones..., op. cit., p. 23.

9. FORAY, D. L'economie de la conaissance (A economia do conhecimento) Paris: La decouverte, 2000. p. 46. traço fundamental é a impossibilidade de ser medido quantitativamente (em termos de custo/benefício), embora seja factível dimensionar sua importância qualitativa em processos de câmbio. O tipo de conhecimento ao qual estamos aludindo é o que Foray ${ }^{9}$ denomina de conhecimento implícito, cujas operações de busca, acesso, circulação, armazenagem e intercâmbio são difíceis de capturar.

Recriar outros modos de organização econômica - tal como se mencionou acima, com respeito às fábricas recuperadas ou assembléias comunais para a tomada de decisões que permitam a sobrevivência - é atitude coletiva de relevân- 
cia, mas se não fosse pensada com projeção estratégica, seria difícil que pudesse subsistir, uma vez que isso implica um processo de aprendizado necessariamente coletivo. Aí o conhecimento se produz através das formas conhecidas como learning by doing e learning by using (aprender fazendo e aprender usando) ${ }^{10}$.

As condições do sistema educativo indicam que a concentração e a produção do conhecimento como um bem na educação pública se debilitou profundamente, o que envolve a possibilidade de que sejam constituídos novos espaços de concentração de conhecimento com uma possível polarização da distribuição desse bem.

A dispersão (no sentido positivo) de uma ação coletiva como a de se organizar para reter uma fonte de trabalho ou tratar de modificar decisões de governo, ao menos no seu ponto de partida, implica a apreensão de um novo conhecimento não concentrado e de difícil manipulação. Esse aprendizado é a resultante do intercâmbio desse bem que não requer transmissão, como único insumo. A informação é uma variável dependente desse processo e a ação, sua portadora: "a ação direta pode ter uma eficácia analítica que vai mais longe que nossas intervenções analíticas"11.

Trata-se de um processo de circulação altamente dinâmico e ubíquo que polarizará ainda mais nossa sociedade ou socializará sua distribuição, desde que não seja atribuído valor estratégico ao conhecimento como um bem.

Não estamos nos referindo à produção de conhecimento deliberado num sistema científico e tecnológico (pesquisa \& desenvolvimento), o qual é, desde sua própria concepção, uma produção deliberada, institucionalizada e com exterioridade visível. Aludimos à que Foray ${ }^{12}$ denomina invenção coletiva.

Dentro da perspectiva da invenção coletiva, o conhecimento produzido não provém de sujeitos singulares nem de organizações fechadas. Sua natureza coletiva manifesta necessariamente que sua propriedade e domínio são amplos e que é quase impraticável medir seu alcance.

Assim, as características-chave da invenção coletiva na sua dimensão informal poderiam sintetizar-se do seguinte modo:

- Ela se produz através de mecanismos informais e espontâneos de intercâmbio, da partilha de conhecimentos e de savoir-faire (saber fazer).

- Ela se produz num plano profissional ou territorial. Esse território preexiste à formação do coletivo e faz emergir convergências, similaridades, ocasiões de reencontro e transação.

- A invenção coletiva é um processo incrementador baseado na difusão dos conhecimentos disponíveis dentro de um coletivo.

- O processo de invenção coletiva não é encerrado por um acordo ou uma instituição central, mas é relativamente espontâneo.

- A formalização da invenção da criação coletiva implica, entre outras questões, a criação de um contorno, de modo que se façam emergir contextos de socialização do conhecimento e do aprendizado coletivo, de maneira concertada também para controlar questões externas engendradas.

Os dispositivos que permitem a circulação e distribuição do conhecimento como um bem podem ser: institucionais, organizacionais, tecnológicos e, fundamentalmente, comunicacionais.
10. Ibid, p. 12. Veja, por exemplo, o AMI (Acordo Multilateral sobre as Inversões), um texto elaborado no contexto da OCDE (Organização para Cooperação e Desenvolvimento Econômico). Pautam-se os direitos imprescritíveis das sociedades transnacionais (que se começou a elaborar em 1995), firmados por 29 países: asseguram-se seus poderes sobre os Estados num capítulochave sobre Direitos dos Inversores, pelo qual, por exemplo, a perda de uma oportunidade de benefício sobre uma inversão será um tipo de prejuízo suficiente para que se lhe outorgue o direito a uma indenização.

11. LAPASSADE, G. Grupos, organizaciones..., op. cit., p. 30.

12. FORAY, D. L'economie de la..., op. cit., p. 43ss. 
No caso da Argentina, essa produção de conhecimento como invenção coletiva - quando já se iniciaram as ações com diferentes modalidades de organização e de gestão coletivas -, assume um valor econômico quando se trata da produção de um conhecimento difícil de elaborar: a produção de uma idéia organizacional. Tornou-se evidente até que ponto a exploração das potencialidades oferecidas pelas novas tecnologias poderia ser freada pela inércia das formas de organização. Há, sem dúvida, um problema de produção do saber organizacional. "É mais fácil e mais rápido aumentar o número de transistores de um microprocessador que conceber um novo conceito organizacional ${ }^{13}$."

No contexto do impulso outorgado pela corporação às TICs (Tecnologias de Informação e Comunicação) enquanto fator de desenvolvimento ${ }^{14}$, aparece como um dos determinantes da mencionada incorporação o aprendizado prévio ou imprescindivelmente correspondente às novas modalidades de organização. Isto não pode ser apreendido de modo superficial, por exemplo, através de um manual de instruções, mas mediante as ações concretas e o intercâmbio das experiências que gradualmente recria comunidades de sentido.

Em nosso caso, tal saber se produz em situação de necessidades não satisfeitas: a organização do delito ou a organização da produção para satisfazer tais necessidades; a organização das demandas às instituições diante da sua própria inércia tem sido factível ante situação-limite gerada pelo neoliberalismo in extenso aplicado na Argentina. Perante a absoluta ausência do Estado, a sociedade se constitui como a ordenadora de sentido também no que diz respeito aos organizadores de bolsões de poder descentralizado, como por exemplo, ante as forças de segurança urbana na posição de planejadoras de tráfico, prostituição, drogas, seqüestros e roubos no contexto de autonomias relativas e dentro de estruturas estatais.

13. FORAY, D.; MAIRESSE, J. Innovations et performance des firmes (Inovações e desempenho das empresas). Paris: Ed. de l’Ecóle des hautes études en sciences sociales, 1999.

14. A OCDE reúne: Suécia, França, Dinamarca, Finlândia, Noruega, Canadá, Reino Unido, Estados Unidos, Países Baixos, Áustria, Bélgica, Austrália, Japão e Itália. Esses países investem no conhecimento (R\&D, softwares e gastos públicos em educação) entre 8 e $11 \%$ do seu $\mathrm{PIB}$. Caso se acrescente a isso $\circ$ gasto particular em educação e formação, essa cifra se elevaria a $10 \%(D$. FORAY, 21).

\section{TICS E CONHECIMENTO}

A incorporação das Tecnologias de Informação e Comunicação - TICs resulta num flanco ineludível a ser incluído na modalidade ou nas modalidades organizativas, que a sociedade argentina possa assumir. Essa incorporação tem sido um dos eixos do desenvolvimento dos países da OCDE na proporção do crescimento do capital intangivel, embora se tenham criado, historicamente, problemas de técnica, de organização e de gestão, que se evidenciam ainda nesses países. Foram desafios gradualmente superados, mediante as gerações tecnológicas seguintes, as quais se esforçaram por resolvê-los.

Os principais problemas dos países pertencentes à OCDE foram as mudanças organizativas necessárias e o desenvolvimento de competências vinculadas à inovação e à flexibilidade para a incorporação de TICs.

No caso da Argentina, trabalhar uma estratégia de desenvolvimento baseada no conhecimento do capital intangível (educação, formação, I\&D - Investigação e Desenvolvimento) contém vantagens relativas e relevantes. Ainda contamos com o recurso da educação pública (é um dos poucos países latino-americanos 
que debilmente consegue sustentá-lo) e, com base na profunda crise surgida em dezembro, deixou-se claro, para a maior parte da população (particularmente os setores da classe média e pequena classe média), que era necessário aprofundar a concepção organizativa da sociedade. Trata-se de um conhecimento tácito produzido pela ação concreta, que demonstra sua produção mediante experiências organizativas produtivas, manifestações coletivas públicas, experiências de enfrentamento, ou criação de alternativas ante a insegurança. Desse modo, tornou-se evidente que existe um tecido institucional o qual pode ser recriado coletivamente, algo que em tempos de estabilidade ou de continuidade resulta invisível. Então, é preciso valorizar a existência - em desenvolvimento - de um bem superlativo, vinculado a um pensamento que abranja alguma estratégia de renascimento do país: o bem conhecimento.

\section{ESTRATÉGIAS DE COMUNICAÇÃO}

A atual crise requer imaginação a fim de ser superada e, basicamente, conhecimento para gerar novas instâncias de organização. Pois bem, organizar-se demanda estratégias de comunicação graduais e flexíveis, que permitam trabalhar a gestão/ação como conhecimento da própria prática. A América Latina se caracterizou historicamente por aprofundar modalidades de pesquisas e desenvolvimento em comunicação vinculadas a iniciativas que pretendem devolver ou ativar o protagonismo popular, através da metodologia da pesquisa-ação, de práticas que articulam a convergência educomunicacional, na busca de instâncias para atingir a socialização do acesso e o uso de novas tecnologias de comunicação com vistas à conformação de redes informáticas.

A capacidade de adaptação, a mobilidade e a flexibilidade enunciadas pelos estudos sobre a incorporação das tecnologias de informação e comunicação como condição sine qua non, são competências para a incorporação de tais tecnologias, informalmente desenvolvidas como conhecimento tácito em nossas sociedades, as quais obrigam o cidadão comum a se adaptar a um presente contínuo de crise, para o qual deve possuir algumas dentre essas competências e assim poder garantir sua sobrevivência. A isto se soma, na presente crise, uma mais-valia; o aprofundamento de um conceito, ou seja, a organização como espaço que é atravessado pelo instituído e a visibilidade de sua contraface: o instituinte como espaço potenciável de recriação organizativa. A tudo isto, deve-se agregar a capacidade técnica para uso e gestão das TICs.

As ações que impliquem a construção, produção e circulação de conhecimento sobre a base de ações e práticas de comunicação, constituem o que poderíamos denominar "gnoseocomunicação".

Nesse caso, referimo-nos especialmente ao conhecimento implícito que se produz em um particular período de crise (cuja especial característica parece ser o aprofundamento da aplicação do sistema neoliberal num país do Terceiro Mundo) que se sustenta em práticas comunicativas para sua circulação, mas 
que, também, poderia ser instituído em alguns aspectos como conhecimento formalizado, a partir da superação do plano da tática no qual ainda se acha, procurando alcançar a conformação de estratégias em comunicação de/para/ com o conhecimento.

"A mídia, hoje em dia, é um veículo fundamental de acesso ao conhecimento e, ademais, contém parte desse conhecimento. Um conhecimento que [...] se oferece sem tempo para analisá-lo com uma certa perspectiva, mas ancorado no contexto social mais próximo e imediato; o que mistura emoções e intelecto; o que chega ao receptor desestruturado e com o denominador comum do conflito”, sustenta Mar de Fontcuberta ${ }^{15}$. Mas, se os meios são aqueles portadores/portantes de maior evidência nas sociedades atuais, os outros portantes de máxima eficácia na hora de recuperar a construção de conhecimento são as ações e práticas de intercâmbio que envolvem com a mediação dos meios de comunicação os lugares-chave de comunicação na produção e circulação do conhecimento tácito e, especialmente, da abertura de condições para a invenção coletiva, como a definimos anteriormente.

\section{TÁTICA E ESTRATÉGIA}

"Na época de crise, o único valor que fica somos nós mesmos" (Saramago). Avaliar um bem produzido coletivamente implicaria, do meu ponto de vista, criar condições para que essa invenção coletiva pudesse ser resgatada e transmitida além das pessoas portadoras dos mencionados conhecimentos. De acordo com os aspectos-chave para tal formalização, é necessário criar instâncias de coordenação, de espaços e tempos para tal conhecimento. Não se trata de centrar necessariamente o conhecimento, mas de contribuir com ferramentas necessárias para uma nova institucionalização, a qual poderia se articular com espaços de conhecimento institucionalizado, como, por exemplo, as universidades.

Entre essas ferramentas, a comunicação se concebe como portadora de conhecimento na medida em que supera o plano da tática no qual se produz predominantemente o mencionado conhecimento, para gerar um salto qualitativo na direção do projeto e da ação como estratégias de comunicação para/ com/de conhecimento.

A necessidade de superar o plano da tática na produção de conhecimento

15. CROVI DRUETTA, Delia (Coord.). Comunicacion y educacion. Perspectiva latinoamericana (Comunicação e educação. Perspectiva latino-americana). México: ILCE, 2002. p. 60.

16. FERNANDEZ, Ana M. (Comp.). Instituciones estalladas (Instituições falidas). Buenos Aires: Eudeba, 1999. sobre a organização da sociedade é um aspecto básico para que a dimensão instituinte, que se destruiu, seja um potenciável recurso de mudança. Diante do invisível mercado, cujo eixo fundamental radica em sua organização internacional, a sociedade deve passar do plano da reação ao plano proativo.

Nesse sentido, formalizar a construção coletiva de conhecimento de organização social e de visibilidade do conceito institucional é também um instrumento para modificar o mecanismo interno que se produz nas nossas instituições. Ana Fernández ${ }^{16}$ alerta, em especial, sobre o mecanismo da falta de fundos, que priva de sentido o espaço público. Este aspecto é a outra face da dimensão instituinte 
potenciável, como recurso de conhecimento e de ação organizativa coletiva. O braço externo que implica o neoliberalismo se complementa com um braço interno, o qual, de dentro das mesmas instituições, opera como privatização do público, num gélido abraço que explode as instituições: "Se nos espaços públicos não há apropriação coletiva regulada, há apropriação selvagem do que me convém, as instituições deixam de ser ordenadoras de sentido e reguladoras de práticas [...]. As instituições são detonadas enquanto funcionam, mas sem a conformação de um coletivo necessariamente heterogêneo que institua tanto seus potenciais enunciativos como seus instituintes da ação no contexto de suas políticas de diversidade"17.

Os mecanismos de mercado terão de continuar sendo desorganizadores de sentido, tal como aconteceu na Argentina, um braço instituído e o mais difícil de visibilizar, na medida que sua identidade fica encoberta na circulação de capitais transnacionais.

Para recuperar e valorizar as ações coletivas, retomo as noções de tática e estratégia de Certeau ${ }^{18}$ como modo de fazer ou lógica de ação, o qual nos coloca na situação de armar nossa caixa de ferramentas para o diagnóstico e para a intervenção como possíveis articuladores de práticas que serão endereçadas futuramente a um plano de estratégia para trabalhar sobre:

- As mudanças que afetaram a temporalidade: a crise tem quebrado a vivência desde o vertiginoso incremento da incerteza que se impôs na vida cotidiana, até a dificuldade para projetar-se, de um presente continuamente em crise, sobre o futuro.

- As mudanças que afetaram os organizadores de sentidos, os quais, desde o seu descentramento, não se reconhecem mais como policentralidades claras, mas apenas vontades que ficam mais perto umas das outras e, ainda, não se compõem como organizações articuladas, tal como afirma Lechner. ${ }^{19}$

O plano da tática constitui a operatória predominante da dimensão instituinte, na medida em que constitui uma prática da vida cotidiana. São suas características:

- Não ter perspectiva de totalidade.

- Não manter distância com respeito ao que faz.

- Depender do tempo presente e operar com improvisação.

- Ser de caráter reativo.

- Não ter um outro como totalidade claramente visível.

Substituir a análise dos aparelhos e das estruturas pela busca de modos de fazer constitui a procura daquelas operações microscópicas que se manifestam como táticas articuladas sobre os detalhes do cotidiano. Certeau afirma que "trata-se de precisar como a criatividade dispersa é tática dos grupos, compondo, no limite, a rede de uma antidisciplina ante uma tecnologia disciplinatória" ${ }^{20}$. De nossa perspectiva, tais táticas se manifestam através de práticas de comunicação concretas.
17. Ibid., p. 26.

18. DE CERTEAU, M L'invention du quotidien. 1. Arts de faire (Invenção do cotidiano. Artes do fazer). Paris: Gallimard, 1990.

19. LECHNER, N. La reforma del Estado y el problema de la conduccion politica (A reforma do Estado e o problema do direcionamento político). En: Perfiles Latinoamericanos. Revista de la Sede México de la Facultad Latinoamericana de Ciencias Sociales. Año 4, n. 7. Dic. 1995.

20. DE CERTEAU, M. L'invention du quotidian... op. cit. 
Para veicular a lógica de ação do instituinte, centralizada na tática dirigida a uma dimensão estratégica, deve-se orientar a operatória em direção aos novos organizadores de sentido, tendo em vista que:

- se elabore conhecimento sobre a externalidade da crise;

- se elabore conhecimento sobre sua interioridade;

- se incorpore o cálculo de relação de forças;

- se faça a aproximação de mecanismos de diagnóstico;

- se transforme o presente contínuo, através de uma lógica de ação proativa, de modo a modificar, a partir da ação, a temporalidade (em direção ao sentido de projeção que envolve a idéia de futuro).

Essa modificação da orientação da ação do plano imediato para a mediação da projeção só é realizável na medida em que o conhecimento tácito se produz na linguagem, na comunicação portadora/portante e organizadora de conhecimento, suficientemente flexível para conter desde as ações aos comportamentos e às regularidades até a explicitação dessas experiências nas redes informáticas.

Pensar em termos da comunicação, em concomitância com a produção/ construção/circulação, armazenamento e socialização do conhecimento, nos obriga a repensar o eterno retorno à centralidade midiática que os comunicadores sociais utilizam como recurso último e inquestionável (por sua visibilidade), na hora de trabalhar sobre o plano das práticas.

O desenvolvimento de um bem superlativo, como é o bem conhecimento, aposta na atual população e na potencialidade das gerações vindouras. Se vincularmos esta questão com as das novas gerações tecnológicas, poderemos dizer que, embora sua capacitação tenha diminuído no país ${ }^{21}$, são elas que manifestam alto interesse e alta disponibilidade para o uso de novas tecnologias (se bem que a atual geração de jovens e adolescentes não teve acesso massivo às TICs para uso individual); elas constituem a outra coluna de que se necessita para sustentar o peso de uma estratégia de renascimento/desenvolvimento baseada no saber.

Ressurgir dessa crise a partir do desenvolvimento baseado no crescimento

21. Na Argentina, $50 \%$ dos jovens não terminam sua escolaridade devido à situação crítica do setor; não têm, igualmente, oportunidades para aperfeiçoarse e aspirar a trabalhos qualificados, coisa que é mais um obstáculo à possibilidade de melhorar suas vidas. (Fonte: Gustavo Fernandez Russo, Diretor Nacional da Juventude DNJ - do Ministério do Desenvolvimento Social da Argentina. Notícias CINU, set./nov. 2001). do capital intangível seria uma oportunidade para que um país que destruiu sucessivas gerações de jovens através do exercício de várias violências (exílio, desaparecimento, morte, guerra, emigrações) gerasse condições para que os jovens pudessem formar suas vidas vinculados à possibilidade de criação de um presente em futuro contínuo. 
Resumo: A função estratégica do conhecimento como principal recurso para o desenvolvimento das capacidades organizativas e das competências comunicativas pode resultar em novos espaços sociais, gerados a partir de uma profunda ruptura social na explosão da crise argentina. As ações que implicam construção, produção e circulação de conhecimento com base em ações e práticas de comunicação é que denominamos de "gnoseocomunicação". Neste caso, referimo-nos, em especial, ao conhecimento implícito que se produz em um período de crise e que, para sua circulação, se sustenta em práticas comunicativas. O conhecimento implícito também poderia consubstanciar-se sob certos aspectos, transformando-se em "conhecimento formal", desde que supere o plano tático em que se encontra para converter-se em estratégias comunicativas para o conhecimento.

Palavras-chave: comunicação, conhecimento, crises, organização, Tecnologias de Informação e Comunicação (TICs).
Abstract: The strategic role of knowledge as the main resource for the development of organizational capability and communication competencies can result in new social space, generated from the deep social rupture during Argentine crisis. The actions that imply knowledge building, production and circulation based on communication actions and practices are what we call "gnoseocommunication". In this case, we refer specially to the implicit knowledge that is produced in a crisis period and which, for its circulation, is sustained upon communication practices. Implicit knowledge could also be consubstantiated under certain aspects, becoming "formal knowledge", since it can surpass the tactical plan in which it is encountered to be converted into communication strategies for knowledge.

Keywords: communication, knowledge, crisis, organization, information and communication technologies. 